\title{
Using Social Support Levels to Predict Sexual Identity Development Among College Students who Identify as a Sexual Minority
}

\author{
Richard A. Brandon-Friedman, MSW, LCSW, LCAC \\ Hea-Won Kim, Ph.D.
}

Indiana University School of Social Work

Corresponding Author:

\author{
Richard A. Brandon-Friedman \\ 902 W. New York St, ES 4138 \\ Indianapolis, IN 46202 \\ rifriedm@iupui.edu
}

This is the author's manuscript of the article published in final edited form as:

Brandon-Friedman, R. A., \& Kim, H.-W. (2016). Using social support levels to predict sexual identity development among college students who identify as a sexual minority. Journal of Gay \& Lesbian Social Services, 28(4), 1-25.

https://doi.org/10.1080/10538720.2016.1221784 


\begin{abstract}
This study examined the impact of five domains of social support (a campus group for individuals who identify as a sexual minority, family, friends, significant others, and faith communities) on eight aspects of sexual minority identity development (identity uncertainty, internalized homonegativity, identity affirmation, acceptance concerns, identity superiority, concealment motivation, identity centrality, and difficulty in the identity development process). Support from a sexuality-specific campus group was the strongest predictor, followed by support from family members. Supports from friends and significant others had no significant impact on any aspect of sexual minority identity development, while faith community support was not correlated with identity development. Identifying as lesbian, bisexual, or as another sexual minority compared to identifying as gay also impacted sexual minority identity development.
\end{abstract}

KEY WORDS: Sexual identity, LGBT, social support, identity development, young adult, adolescent 


\section{Using Social Support Levels to Predict Sexual Identity Development Among}

College Students who Identify as a Sexual Minority

Individuals who identify as a sexual minority encompass up to $15 \%$ of the young adult population (Savin-Williams \& Ream, 2007). These individuals have oftentimes forged sexual identities in a societal context that stigmatizes individuals who identify as a sexual minority and perpetuates social norms and mores that pathologize sexual and gender variance (D'Emilio \& Freedman, 1998). Even though homosexuality was eliminated as a diagnosable mental disorder by the American Psychiatric Association in 1973, many individuals continue to see a sexual minority identity as an indicator of a disorder (Drescher, 2010), leading to negative psychosocial consequences for individuals who identify as a sexual minority such as increased social isolation, mental health concerns, and difficulties developing a coherent sense of self (King et al., 2008; Rosario, Schrimshaw, \& Hunter, 2011). The effects of these negative societal messages are perhaps most impactful during adolescence and young adulthood, as this is the time period in which individuals become more socially aware and begin developing the identities and interpersonal relationship styles that will affect the rest of their lives (Erikson, 1963, 1968).

Despite the progress that has been made toward better understanding the sexual minority identity formation processes, significant empirical gaps remain regarding how best to support individuals who identify as a sexual minority as they develop their sexual identities. This paucity of knowledge is particularly concerning as navigating the sexual minority identity development process is viewed as a critical step toward building a positive sexual minority identity and an integrated self-concept (Bilodeau \& Renn, 2005; Cass, 1979; Troiden, 1988). Much of the literature regarding assisting youth who identify as a sexual minority with this process has suggested the importance of various forms of psychosocial support, but little research has examined the manner through which these supports contribute to positive outcomes. 
Accordingly, the purpose of this study was to examine the effects of various types of social supports on sexual minority identity formation in young adults in order to further explicate which social support structures promote or hinder the formation of an integrated sexual minority identity.

\section{Literature Review}

The importance of successfully progressing through the identity formation process has been documented since Erikson (1963) enumerated his model of psychosocial development. Within this model, the process of sexual identity development amplifies during the Identity vs. Confusion and Intimacy vs. Isolation stages, which occur during early to mid-adolescence and late adolescence to young adulthood, respectively. At these times, an individual must first develop a cohesive sense of self, which will form the core of his or her later identity; a failure to do so will leave him or her unable to achieve individuality and self-direction. After completing that process, one must then master the ability to form intimate and loving relationships. If unable to do so, one will be unable to form lasting and fulfilling relationships (Erikson, 1963, 1968).

Building upon Erikson's stage-based model of identity ontogeny, other researchers have examined the development of other aspects of individuals' identities, including racial identities (e.g., Winbush, 1977), ethnic identities (e.g., Umaña-Taylor, Yazedjian, \& Bámaca-Gómez, 2004), spiritual identities (e.g., Tate, 2007), sexual minority identities (e.g., Cass, 1984;

D'Augelli, 1994; Troiden, 1988), and, more recently, heterosexual identities (e.g., Morgan, 2011). While the various sexual minority identity development models that have been developed in the past thirty years have varied in their foci and the intra- and inter-personal components included, they generally encompass several aspects of individuals' lives, including the psychosocial self, sexual fantasies, sexual actions, and romantic interests (Savin-Williams, 2005). While these aspects form the core of most individuals' sexual identities, given the 
hegemonic place of heterosexuality in contemporary culture, individuals who identify as a sexual minority must go through a process in which they come to identify as a member of a commonly disparaged group (Bilodeau \& Renn, 2005).

The first prominent homosexual ${ }^{1}$ identity development model was developed by Cass (1979) and included six stages. It outlined a series of processes by which individuals develop and integrate their homosexual identities, beginning with individuals' initial confusion regarding their sexuality and their recognition that they might be homosexual ('First Awareness'), and ending with them developing pride in their homosexual identities ('Identity Synthesis'). In her writings, Cass emphasized that this identity development process involves a change in personal perception in which a homosexual identity replaces a previously "assumed" heterosexual identity. With this recognition, Cass suggested that it is not enough for individuals to change intrapsychically, but their environments must also accept and support these changes or else new, more supportive environments must be located.

Troiden (1988) developed the second prominent model, one which further highlighted the sense of confusion and turmoil that may be present in individuals as they struggle with the acceptance of their homosexual identity and how societal expectations and events can influence the homosexual identity formation process. Taking a more sociological perspective, Troiden accentuated the importance of the surrounding environment on the homosexual identity formation process by taking into account phenomena such as stigma. Stigma serves to devalue individuals' emerging identities, creating discord between individuals' personas and the normative social discourse. In discussing how individuals counteract the negative effects of their devalued social position, Troiden emphasized the importance of meeting other homosexuals and

\footnotetext{
${ }^{1}$ In order to remain faithful to the original theories, reports, and studies, throughout this paper we have used the original authors' manners of referring to non-heterosexually-identified individuals.
} 
developing positive bonds with them, thereby diminishing feelings of isolation and alienation. He also stressed the benefits of the personal and social integration of their homosexual identities, noting the benefits and relief that occur as negative narratives are mitigated and integration of disparate aspects of identities occurs. As such, Troiden affirmed Cass' initial recognition that the development of homosexual identities involves not only individualistic perceptions of one's sexual self as being different from the heterosexual majority, but also a public recognition and pronouncement of one's homosexual self within a social context.

Other models have been developed that further emphasize the various social aspects of the homosexual identity formation process, such as D'Augelli's (1994), which further recognized the importance of the social environment and how it affects the expression of sexual minority identities, and Fassinger's (1998), which differentiated between individuals' internal sexual identities and their group membership/role in the lesbian, gay, and bisexual (LGB) community. Additional models have also been developed that have recognized the differential experiences of subgroups of sexual minority individuals such as lesbians (e.g., Eliason, 1996), bisexuals (e.g., Fox, 1995), and individuals in racial and ethnic minority groups that identify as gay (e.g., Hunter, 2010). Further, alternate models have recognized the importance of a variety of types of support that must be offered since individuals or groups may proceed through the sexual minority identity development process in different manners (Rosario, Schrimshaw, \& Hunter, 2004).

Despite the prominence of sexual minority identity development models, it must be noted that researchers such as Savin-Williams $(2001,2005)$ and Diamond (2008) have criticized the stage-based developmental paradigm, emphasizing the socially constructed nature of sexual identities and suggesting that researchers may be over-emphasizing the importance of sexual identities. On the other hand, Calzo, Antonucci, Mays, and Cochran (2011) found support for the 
primacy of self-identity in homosexual development amongst their study population, while others have emphasized the salience of sexual identities for adolescents (Carrera, DePalma, \& Lameiras, 2012; Morgan, 2011).

\section{Implications of Compromised Sexual Identity Formation}

Not developing an integrated sexual minority identity can lead to individuals failing to understand themselves as coherent sexual beings (Cass, 1984; Troiden, 1988) and facilitate the development of internalized homonegativity, which is defined as the internalization of societal anti-homosexual attitudes (Shidlo, 1994). Research has documented correlations between internalized homonegativity and loneliness, limited social interactions suicidality, substance use/abuse, psychological distress, intimacy barriers, and sexual risk behaviors among youths under age 25 (Berg, Munthe-Kaas, \& Ross, 2016; Theodore et al., 2013).

Many of these difficulties can be understood through the framework of sexual minority identity formation. As individuals begin to understand and grasp the effects of their differences from those around them, feelings of isolation can occur (Johnson \& Amella, 2014). In addition, prior to initiating the coming out process, there can be significant discord between the individuals' internal identities and their external presentation, a dissonance that has been correlated with negative mental health effects (Meyer, 2013). While some of this incongruity may be relieved by the affirmation of sexual minority identities that occurs during the coming out process, many youth also experience significant anxiety related to the impending process of disclosing their sexual minority identity to others, further contributing to difficulties with psychosocial functioning (LaSala, 2012). Likewise, Ford (2003) noted that significant negative psychosocial effects can occur if adolescents are not supported during the coming out process. 


\section{Social Supports Impacting Sexual Minority Identity Development}

Regardless of sexual identity, adolescence and early adulthood are times in which social struggles and pressures are particularly high. Fortunately, social and familial supports have been shown to be a protective factor for adolescents faced with social or psychological struggles or stress (Konishi \& Hymel, 2009). On the other hand, Hombrados-Mendieta et al. (2011) examined the various impacts that families, peers, social institutions, and professionals have on ameliorating stress among individuals in different age groups and suggested that the impact of different arenas of support changes as individuals age, highlighting the needs for research specifically targeted toward adolescents and young adults.

For LGB-identified individuals, Brown and Colbourne (2005) noted the particular importance of a variety of supports including community agency services, education services, social opportunities, familial support, and gay and ally community supports for building resiliency, suggesting that such supports lead to increases in "truth in being" (being true to oneself in spite of cultural negativity) and feelings of empowerment, validation, and greater sexuality-specific health competency. Likewise, Doty, Willoughby, Lindahl, and Malik (2010) highlighted the importance of sexuality-related supports from other LGB youth, noting the heightened struggles of LGB individuals due to "sexuality related stress." They also noted the difficulties in receiving support for sexuality-related stress from heterosexual peers and family members who may hold negative attitudes toward sexual minorities, lack knowledge related to alternate sexual issues, and/or struggle to understand the experiences of individuals who identify as a sexual minority. Ultimately, they found that the inability of many heterosexually-identified individuals to fully understand the experiences of LGB youth can actually perpetuate the sexuality-related stress that LGB youth endure, no matter how well-intended their actions may be. 
In addition, while Mishna, Newman, Daley and Solomon (2009) found that bullying based on lesbian, gay, bisexual, and transgender (LGBT) identification was perceived to be widespread across life domains, they also noted that institutional supports for LGBT-identified individuals were effective ways to combat bullying. Further research has indicated that even a small network of supportive peers can make a significant difference in the lives of youths who identify as sexual minorities and that through engagement with peers within "safe spaces" provided by school or community groups they can begin to explore their sexual minority identities in a nonjudgmental arena, allowing them to engage in the developmental processes that most other youths do within everyday peer interactions (Doty et al., 2010; Rosario, Schrimshaw, $\&$ Hunter, 2008). Further, research has demonstrated the positive impact that school- and community based support programs such as gay-straight alliances and peer support groups have on lesbian, gay, bisexual, transgender, and questioning (LGBTQ) high school students and those between the ages of 13 and 22 (McCormick, Schmidt, \& Clifton, 2014; Walls, Wisneski, \& Kane, 2013). What has not been clearly articulated, however, is the relationship between these supports and sexual minority identity development, rather than overall positive social experiences.

On an intrapersonal level, researchers have also focused on the roles that religion and spirituality have in the lives of individuals who identify as a sexual minority. While some individuals compartmentalize the spiritual/religious and sexual aspects of their lives, others have been able to integrate the two and research has suggested that this integration advances the psychosocial development of gay men in college (Dunn et al., 2015). Despite the negative stance that many religions have toward non-heterosexuality and some research that has linked religious commitment to negative psychological well-being, other research has indicated that religion and spirituality remain salient in the lives of many college-age individuals who identify as a sexual 
minority and may form a protective barrier against psychosocial difficulties. Researchers have postulated that this may be because the messages of unconditional love, acceptance, and rejection of oppression that form the corner-stone of many religious traditions may resonate with the social realities and needs of individuals who identify as a sexual minority (Meanley, Pingel, \& Bauermeister, 2015; Yarhouse, Stratton, Dean, \& Brooke, 2009). Yet, little quantitative research has considered the effect of these aspects of individuals' lives on the development of their sexual minority identities.

Despite the lack of empirical investigation into the effects of social supports on sexual minority identity development, theoretical developmental models have been used to encourage development of programs, supports, and interventions with various social systems such as families, schools, social service providers, religious organizations, and communities (e.g., Mallon, 2010; Roe, 2015; Walls et al., 2013). Within this literature, the support provided by individuals, groups, and programs has been assumed to be able to meet the sexual minority identity developmental needs of the attendant individuals (Tharinger \& Wells, 2000). Yet, while research has spot-lighted the positive effects of organizations geared toward adolescents and young adults who identify as a sexual minority (Roe, 2015; Walls et al., 2013), aside from the work of Sheets and Mohr (2009) there have been no attempts to systematically consider which types of support positively or negatively impact the development of a sexual minority identity. Responding to the lack of literature examining the connection of social supports to sexual minority identity formation, this study was designed to evaluate which areas of social support best predicted eight domains of sexual minority identity formation. 


\section{Method}

\section{Recruitment}

Participants in this exploratory, cross-sectional study consisted of students enrolled in post-secondary educational institutions in a Midwestern state that were between 18 and 24 years of age and self-identified as sexual minorities. Due to the distinction between sexual identity and gender identity, individuals who identified as transgender were included only if they also identified as sexual minorities. Participants were recruited in two ways. First, campus websites and online sexual minority resource directories were searched to obtain the names and contact information for leaders of campus groups for individuals who identify as a sexual minority. These leaders were e-mailed and asked to forward an invitational e-mail to their members explaining the study and containing a link to the web-based survey. Some universities did not list the names of the groups' leader(s) but instead had a general mailbox for the organization; if this was the case, the e-mail was sent to that general e-mail address. In all, 39 organizations at eight institutions were contacted.

The second recruitment strategy involved contacting administrators of academic programs from the state's postsecondary educational institutions and requesting that they distribute the invitational email and recruitment letter to their departmental listserv and/or email students enrolled in their departments' courses. Departmental directors were identified by reviewing university and college websites, contacting academic departments to request contact information of program administrators, and reaching out to faculty and staff who may have been able to assist with identifying academic program administrators. In all, 54 directors representing 27 departments at eight universities were contacted and requested to forward the invitational email to students. As the gatekeepers for the support groups and departmental listservs were not asked to inform the authors if they forwarded the study invitations, determining the degree to 
which the survey was distributed was not possible, although several support group leaders and departmental administrators informed the authors that they had forwarded the email. Approval for this study was granted by the Institutional Review Board of the authors' university.

\section{Measures}

Social Support. A modified version of the Multidimensional Scale of Perceived Social Support (MSPSS; Zimet, Dahlem, Zimet, \& Farley, 1988; Available in Appendix A) was used to measure participants' perceptions of their levels of social support. Perceived social supports were used instead of an objective measure of the number or types of supports individuals have as they are a better determinant of improved psychosocial functioning due to their more direct connection with the psyche of the individual (Zimet et al., 1988). The original MSPSS measures perceived social supports in three domains: those from family, friends, and significant others. Two additional domains of social support - those of a religious community and a campus-based group for individuals who identify as a sexual minority - were added for this study based on literature that has indicated their importance for sexual minority identity formation (e.g., Asakura, 2010; Doty et al., 2010; Kubicek et al., 2009; Sheets \& Mohr, 2009; Wright \& Perry, 2006).

The two new subscales were developed in two ways. First, when possible the basic wording of the three original scales was used. For example, "I have a special person who is a real source of comfort to me" was modified to "My faith community is a source of comfort to me." When this was not possible or when it was desirable to examine other aspects of the relationship, prompts were created by the first author. The new prompts were reviewed by others, including the second author and the first author of the original MSPSS, for face validity. In order to remain consistent with the development of the original MSPSS, the only aspect of the directions 
modified for this study was that participants were instructed to consider each domain's support only as it related to the development of their sexual minority identity.

The modified MSPSS scale included 20 items, encompassing a total of five subscales of four items each: Family Support, Friends Support, Significant Other Support, Faith Community Support, and Campus-based Group for Individuals who Identify as a Sexual Minority. Prompts focused on the degree to which individuals felt supported by the identified support system and were rated on a Likert scale from 1 to 7, with 1 representing Very Strongly Disagree and 7 representing Very Strongly Agree. Thus, higher scores on the MSPSS scales indicated a greater amount of perceived social support from that arena. A "not applicable" response option was added so individuals could skip questions that were not relevant to them (i.e., if they did not have a significant other). Following common usage of the scale, the participants self-defined the individuals included in each group (i.e., a significant other could be a boyfriend/girlfriend, dating partner, or spouse; Canty-Mitchell \& Zimet, 2000). Cronbach's alphas were tested for each arena of support and were found to be high; Family Support, .94; Friends Support, .92; Significant Other Support, .96; Faith Community Support, .96; and Campus-based Group for Individuals who Identify as a Sexual Minority, .96. A summary score was calculated for each subscale for use in analysis.

Lesbian, Gay, and Bisexual Identity Development. To measure sexual minority identity formation, four subscales from Mohr and Kendra's (2011) Lesbian, Gay, and Bisexual Identity Scale (LGBIS) were utilized. The LGBIS, a revised and extended version of the original Lesbian and Gay Identity Scale (Mohr \& Fassinger, 2000), was chosen because of its multidimensional approach to sexual minority identity formation in young adults and the original authors' suggestion that it would be useful to determine mechanisms by which identity development can be influenced or strengthened. While the scale was initially developed with only lesbian, gay, 
and bisexual-identified individuals, for this study individuals who identified as sexual minority but not as gay, lesbian, or bisexual were also included. Other approaches used in research utilizing this scale have included recategorizing individuals who identified as other than lesbian, gay, or bisexual as lesbian, gay, or bisexual based on their gender or excluding them entirely from analysis. As this study sought to examine differences in aspects of sexual minority identity development based on identity, a decision was made to divide individuals into self-identified categories of gay, lesbian, bisexual, and other sexual minority. The scale includes 27 items organized into eight subscales that provide a thorough picture of various aspects of the sexual minority identity development progress of individuals.

For this study, all eight subscales were used, Identity Uncertainty (four items), which reflected individuals' uncertainty about their sexual identities; Internalized Homonegativity (three items), which explored the level of negativity individuals felt about their own sexual identities; Identity Affirmation (three items), which assessed the degree of positive affirmation individuals experienced regarding their sexual identity; Acceptance Concerns (three items), which measured the degree to which individuals believe they may be stigmatized by others; Identity Superiority (three items), which examined individuals' beliefs about individuals who identify as a sexual minority being superior to those who identify as being in the sexual majority; Concealment Motivation (three items), which measured the individuals' desire to conceal their sexual minority identity from others; Identity Centrality (five items), which reflected the degree to which individuals view their sexual minority identities to be a central part of their overall identity; and Difficult Process (three items), which explored the individuals' perceptions of the difficulty of developing their identity as a sexual minority. 
Similar to the MSPSS, each item was rated on a Likert scale from 1 (Very Strongly Disagree) to 7 (Very Strongly Agree), with higher scores representing a greater degree of that scale (i.e., a higher score on Identity Centrality indicates that the individual's identity as a sexual minority is more central to his or her overall identity, whereas a higher score on Difficult Process indicates the individual had more difficulty navigating the sexual identity formation process). Cronbach's alphas were calculated for each subscale and found to be adequately high: Identity Uncertainty, .87; Internalized Homonegativity, .90; Identity Affirmation, .94; Acceptance Concerns, .79; Identity Superiority, .80; Concealment Motivation, .86; Identity Centrality, .78; and Difficult Process, .81 , indicating that the subscales were reliable. A summary score was calculated for each subscale.

\section{Data Analysis}

Correlational analysis of the five MSPSS subscales indicated that the faith subscale was unrelated to any of the aspects of sexual minority identity development measured, so it was excluded from the final analysis, leaving four MSPSS predictor variables (Table 1). All independent variables were checked for multicollinearity and other violations of the statistical assumptions of multiple regression and no concerns were identified. The distributions of scores on the Friends Support, Significant Other Support, Campus Group for Individuals Who Identify as a Sexual Minority Support, and Identity Affirmation were significantly negatively skewed so a reflection and logarithmic transformation were completed prior to statistical calculations. In addition, Identity Uncertainty, Internalized Homonegativity, Identity Superiority, and Faith Community Support were significantly positively skewed so a logarithmic transformation was completed prior to regression analysis, while the negative skewness for Identity Centrality was addressed using reflection and square root transformation, building upon a procedure previously used by the scale's original author in Sheets and Mohr (2009). 


\section{[INSERT TABLE 1]}

Three-step hierarchical multiple regression analyses were completed for each dependent variable. A variable of the time since initial disclosure of the participants' sexual minority identity to others was entered as the first step since disclosure had been identified as a possible confounding variable in prior studies of sexual minority identity development (e.g., Halpin \& Allen, 2004; Rosario, Schrimshaw, Hunter, \& Braun, 2006). This variable was entered as a continuous variable based on participants' written-in length of time since they had initially disclosed their sexual minority identity to another person. The second step added participants' self-identified sexual minority category (gay, lesbian, bisexual, or other sexual minority), while the third step further added the four domains of support.

\section{Results}

\section{Participants}

There were 232 individuals who initially responded to the survey; however, 69 respondents did not meet the inclusionary criteria, 32 of whom identified as heterosexual, an additional 32 of whom were outside the age range, and five of whom were not currently enrolled at a college or university. In addition, the data were removed from eight respondents who only completed parts of the demographics sections and from 24 respondents who did not complete the LGBIS portion of the survey. Finally, the data for two additional individuals were removed due to being significant outliers, leaving a final sample size of 129 . Results of chi-square and t-test comparisons between those who only completed a portion of the survey and those who completed it in its entirety indicated no significant differences on any demographic measures. Individuals who did not complete a subscale of the MSPSS were excluded from that regression analysis. As a result, the data from 70 participants were used in the regression analyses. 
Demographics of Study Participants. The demographics and sexual and gender identities of the participants are shown in Table 2. Individuals who identified as a sexual minority but not as gay, lesbian, or bisexual were retained in a fourth category of "other sexual minority." Overall, the majority of study participants were female (63.6\%), and they clustered on the younger end of the 18 -to- 24 age range, with more than $50 \%$ below age 20 (mean age $=20.64$, $\mathrm{SD}=1.53$ ). Overwhelmingly, study participants were White, accounting for $87.5 \%$ of respondents, and most were of a non-Hispanic ethnicity (92.2\%). A majority of respondents (67.4\%) reported not subscribing to any kind of faith tradition, while more than half of the respondents (57.4\%) participated in a campus group for individuals who identify as a sexual minority. Approximately equal numbers of participants identified as gay (24.8\%) and lesbian (26.4\%), while $31.8 \%$ identified as bisexual and $17.1 \%$ identified as another category of sexual minority. The mean amount of time since respondents disclosed their sexual minority identity to others was 3.99 years $\left(\mathrm{SD}=2.85\right.$, range $0.00^{2}$ to 15.08 years).

\section{[INSERT TABLE 2]}

Identity Uncertainty. The first model was insignificant, $F(1,68)=.822, p>.05 ; R^{2}=$ $1.2 \%$ (Table 3), while the second model was significant, $F(3,65)=2.691, p<.05 ; \Delta R^{2}=13.0 \%$, with those who identified as bisexual $(\beta=.40, p<.01)$ or as having another sexual minority identity $(\beta=.40, p<.01)$ feeling more uncertainty about their identities. When the additional predictors of the four MSPSS support scales were added, the model was no longer significant, $F(4,61)=1.53, p>.05 ; R^{2}=16.8 \%, \Delta R^{2}=2.5 \%$. In the third model, the same two sexual minority identities remained the strongest predictors; thus, for the individuals in this study, identifying as either bisexual or as other than gay, lesbian, or bisexual contributed to greater

\footnotetext{
${ }^{2}$ A 0.00 in Time Since Disclosure indicates that the individual had not yet disclosed his or her sexual identity to others as of the time the survey was taken.
} 
identity uncertainty than identifying as gay. None of the arenas of perceived supports had any significant impact on this aspect of sexual minority identity development.

\section{[INSERT TABLE 3]}

Internalized Homonegativity. For Internalized Homonegativity, the first model was not significant, $F(1,68)=.521, p>.05 ; R^{2}=0.8 \%$ (Table 3), nor was the second model, $F(3,65)=$ $1.26, p>.05 ; \Delta R^{2}=6.4 \%$. When the additional predictors of the four MSPSS support scales were added, the model was significant, $F(4,61)=2.79, p<.05 ; \Delta R^{2}=19.6 \%$. In the third model, the predictors most associated with reduced internalized homonegativity were perceived supports from a campus group for individuals who identify as a sexual minority $(\beta=-.36, p<.01)$ and from family members $(\beta=-.26, p<05)$. These results indicate that both supports from a campus group for individuals who identify as a sexual minority and their families contribute to a reduction of the internalization of the negative messages that individuals who identify as a sexual minority often receive from society regarding their sexual minority identities.

Identity Affirmation. For Identity Affirmation, the first model was not significant, $F(1,68)$ $=.119, p>.05 ; R^{2}=0.2 \%$ (Table 3 ), nor was the second model, $F(3,65)=.607, p>.05 ; \Delta R^{2}=$ $3.4 \%$. When the additional predictors of the four MSPSS support scales were added, the model was significant, $F(4,61)=3.41, p<.001 ; \Delta R^{2}=30.5 \%$. In the third model, the presence of a campus group for individuals who identify as a sexual minority was the only significant predictor $(\beta=.55, p<.001)$. This indicates that the presence of a campus group for individuals who identify as a sexual minority is especially beneficial in terms of helping students who identify as a sexual minority have a positive view of their sexual identity. 
Acceptance Concerns. In terms of Acceptance Concerns, the first model was not significant, $F(1,68)=.001, p>.05 ; R^{2}=0.0 \%$ (Table 3 ). The second model was also not significant, $\underline{F}(3,65)=.149, p>.05 ; \Delta R^{2}=0.9 \%$. When the additional predictors of the four MSPSS support scales were added, the model was significant, $F(4,61)=2.425, p<.05 ; \Delta R^{2}=$ $23.2 \%$. In the third model, while the model as a whole was significant, none of the individual predictors were significant, although family supports approached significance $(\beta=-.23, p<.10)$. While none of the arenas of social support were significant themselves, the overall presence of perceived supports contributed to a decrease in concerns about others accepting individuals' sexual minority identities.

Identity Superiority. The first model was not significant, $F(1,68)=1.767, p>.05 ; R^{2}=$ $2.5 \%$ (Table 3), while the second model was significant, $F(3,65)=4.272, p<.01 ; \Delta R^{2}=18.3 \%$. When the additional predictors of the four MSPSS support scales were added, the model remained significant though the change in $F$ was not significant, $F(4,61)=2.580, p>.05 ; \Delta R^{2}=$ $4.5 \%$. In the second model identifying as lesbian or as bisexual were both significant $(\beta=-.43$, $p<.01 ; \beta=-.51, p<.01$, respectively), both of which remained significant in the third model ( $\beta$ $=-.46, p<.01 ; \beta=-.58, p<.001$, respectively). Thus, identifying as lesbian or bisexual contributes to reduced feelings of identity superiority.

Concealment Motivation. The first model was not a significant predictor, $F(1,68)=.865$, $p>.05 ; R^{2}=0.0 \%$ (Table 3), while the second model approached significance, $F(3,65)=2.193$, $p<.10 ; \Delta R^{2}=11.8 \%$. The third model was then not significant $F(4,61)=1.213, p>.05 ; \Delta R^{2}=$ $1.8 \%$. This finding indicates that neither individuals' sexual identity category nor their levels of support reduce their concealment motivation. It should be noted, however, that the second model's approach of significance and significance in change from Model 1 indicates a difference between individuals' motivation to conceal their sexual minority identity based upon their sexual 
identity category (the difference appears to be for individuals who identify as bisexual, as their level of significance in Step $2=.127)$.

Identity Centrality. None of the models were significant predictors of Identity Centrality, $F(1,68)=.018, p>.05 ; R^{2}=0.0 \% ; F(3,65)=.576, p>.05 ; \Delta R^{2}=3.4 \% ; F(4,61)=1.240, p>.05 ;$ $\Delta R^{2}=10.6 \%$, respectively (Table 3). Despite the lack of significance of the entire model, it should be noted that supports from a campus-based group for sexual minority students significantly increased identity centrality $(\beta=-.35, p<.05)$, indicating its importance for this aspect of identity development.

Difficult Process. In terms of the difficulty of developing a sexual minority identity, neither the first nor second model were significant, $F(1,68)=1.023, p>.05, \mathrm{R}^{2}=1.5 \% ; F(3,65)$ $=.295, p>.05, \Delta R^{2}=0.3 \%$, respectively (Table 3 ). The third model approached significance, $F(4,61)=.249, p<.10, \Delta R^{2}=13.0 \%$, with supports from a campus-based group for individuals who identify as a sexual minority also predicting less difficulty, even if not at the traditional $p$ value $(\beta=-.28, p<.10)$.

\section{Discussion}

This study sought to determine which arenas of social supports predicted various aspects of the sexual minority identity development process among young adults attending institutions of higher education. With a more nuanced understanding of the types of social supports that assist in sexual minority identity development, programs can be designed to address specific aspects of the sexual minority identity formation process. Such targeted interventions would not only help individuals progress through this essential process, but would also help reduce the negative effects of a compromised, unintegrated sexual minority identity.

For the individuals in this study, of the four arenas of supports included in the final analyses, a campus group for individuals who identify as a sexual minority had the largest 
predictive effects on sexual minority identity development, contributing to reduced acceptance concerns, positive sexual minority identity affirmation, reduced internalized homonegativity, and increased identity centrality, and approaching significance on reducing the difficulty of developing a sexual minority identity. Previous research indicated the importance of individuals who are struggling with their sexual identity meeting others that are experiencing the same struggles (Asakura, 2010; Sheets \& Mohr, 2009; Wright \& Perry, 2006), much as the authors of the early developmental models suggested, and the findings of this study further contribute to a recognition of the importance of sexuality-specific supports. It is likely that the universalizing experience of interactions with others who may be going through the same identity development process allows individuals to recognize that they are not alone, provides a sense that it is possible to navigate the difficult sexual minority identity development process, and allows for the construction of supportive social structures, much in the same way as other peer-administered support groups such as Alcoholics Anonymous assist their members (Groh, Jason, \& Keys, 2008).

These findings also compliment the previous findings of Sheets and Mohr (2009) and Doty et al. (2010), both of which identified the importance of sexuality-related supports for individuals who identify as a sexual minority of similar ages to this study's participants. They also further support the theoretical work of Fetner, Elafros, Bortolin, and Drechsler (2012), who suggested the salience of the sociological concept of a "safe-space" for LGBTQ-identified youth and their allies, and Asakura (2010) who explored the concept of specialized Queer Youth Spaces and the ways they could contribute to positive social experiences queer youth. Many larger universities are moving toward the development of support centers and diversity offices specifically geared toward individuals who identify as a sexual minority (Marine, 2011), and the findings of this research support the development of these university resources. In addition, 
while this study was conducted using university students, it is reasonable to infer that the findings advance the importance of sexuality-related supports in other school environments, adding credence to calls for wide spread development of gay-straight alliances in American schools of all educational levels (Kosciw, Greytak, Bartkiewicz, Boesen, \& Palmer, 2011; McCormick et al., 2014; Walls et al., 2013).

Given the struggles that many schools, particularly those in more rural and conservative areas, have had in creating and maintaining support groups within the school (Palmer, Kosciw, \& Bartkiewicz, 2012), significant efforts to create safe sexuality-related spaces for youths outside of the school environment may be required. While this study examined only campus-based groups for individuals who identify as a sexual minority, it is reasonable to suggest that community-based support groups would be beneficial in the same manner. Even if a larger scale endeavor such as a sexual minority community center may be unfeasible due to monetary and population constraints, providing dedicated spaces such as support groups for individuals who identify as a sexual minority would be beneficial. Several gay-affirming churches and neighborhood community centers have begun to develop groups like this, and their efforts should be further supported. In addition, outside groups such as community mental health centers or youth-serving agencies should consider the possibility of running a monthly support group. This research has shown that these supports are important for the development of a positive sexual minority identity, and efforts to further develop them should be increased.

The second most influential domain of support was that of family members. Given that family members represent the core components of most individuals' microsystems, it makes sense that higher levels of sexuality-related supports from these family members result in both lower levels of concern about others accepting the individuals' sexual minority identities and reduced homonegativity. These findings coincide with previous studies such as that of Brown 
and Colbourne (2005), which suggested that familial supports are protective factors against larger-scale homophobia and the effects of negative social messages regarding sexual minority identities, and Eisenberg and Resnick's work (2006), which indicated that family connectedness is a protective factor against suicidality for LGB youths. In addition, Elizur and Mintzer (2001) found that family supports contributed to a greater willingness to disclose a sexual minority identity to others, itself an indicator of positive sexual minority identity development.

Teachers, social workers, clergy, and other youth service workers need to be educated on ways in which they can aid families in coming to terms with the sexual minority identity of other members of their families and developing the skills necessary to support those family members. Some established resources that are available for parents, family members, service providers, and peers include PFLAG (www.pflag.org), True Colors (www.ourtruecolors.org), and the Child Welfare League of America (http://www.cwla.org/our-work/advocacy/race-cultureidentity/lgbtq-issues-in-child-welfare/), and these should be consulted and their materials made available to those in need. Campos' (2005) book on working with gay and lesbian youths for teachers, counselors, and administrators is also a valuable resource for educators at all levels. Furthermore, Gottlieb's (2005) edited book that contains stories about how individuals dealt with having a gay or lesbian sibling may be helpful for other family members. Developing a supportive home environment may help create a buffer for individuals who identify as a sexual minority who are dealing with social stresses outside the home and help with positive sexual minority identity development (Bregman, Malik, Page, Makynen, \& Lindahl, 2013).

In this study, supports from friends had no predictive effect on any domain of sexual minority identity formation. Despite the significant amount of work that has been done to influence the attitudes and behaviors of peers and to increase the acceptance of those with sexual minority identities within many social realms (e.g., through nondiscrimination policies and social 
media campaigns), for these participants, the support of friends had no effect on any of the considered aspects of sexual minority identity formation. This finding was unexpected, given the proliferation of programs dedicated to improving the overall social environments for youths who identify as a sexual minority. One explanation may be that this study did not specify the sexual identities of the friends providing the support. When examining the effects of types of social supports on other psychosocial outcome variables, both Sheets and Mohr (2009) and Doty et al. (2010) found significant interactions between friends' sexual identities, with support from friends who identify as heterosexual and friends who identify as a sexual minority impacting different outcome variables. This study's inability to differentiate between supports from the two groups may have led to the non-significant finding.

The finding that none of the domains of support affected Identity Uncertainty or Concealment Motivation was also unexpected, given the emphasis that some groups for individuals who identify as a sexual minority, families, and society place on determining and labeling sexual identities and on disclosing individuals' sexual identity labels to others (DiFulvio, 2011; Savin-Williams, 2005). With the contemporary media attention on sexual minorities and the ability of individuals to explore their identities online prior to disclosing their sexual minority identity to others in their lives, it may be that individuals are more certain of their sexual minority identities before disclosing it to others than when sexuality was not discussed as openly (Craig \& McInroy, 2014; Grierson \& Smith, 2005). Given that this study only examined individuals who already self-identified as sexual minorities, the participants may have all already had solidified sexual minority identities, thereby eliminating the ability of any types of supports to further contribute to their sexual minority identity development.

It is important that the findings of this study are not construed to suggest that efforts to improve the overall social environment for individuals who identify as a sexual minority are not 
needed. This study looked only at the effects of social supports on various aspects of sexual minority identity development, not on the overall well-being of individuals who identify as a sexual minority. The importance of positive school and community environments for the safety, social and emotional well-being, postsecondary educational success, and career development of individuals who identify as a sexual minority has been well-documented (e.g., Fine, 2016; Kosciw et al., 2011; Roe, 2015; Schmidt, Miles, \& Welsh, 2011; Walls et al., 2013), and the positive impact demonstrated should not be depreciated. Instead, further research may be needed to examine the processes by which these supports are helpful and the reasons these social supports did not contribute to positive sexual minority identity development.

Supports from significant others also had no predictive effect on any domain of sexual minority identity formation for the individuals in this sample, while supports from faith communities were not correlated with any aspect of sexual minority identity formation. For the former, although Zimet et al. (1988) suggested that participants be able to self-define who constituted a significant other, the variability in the participants' definitions may have affected the results. In terms of the lack of effects from faith communities, the low number of participants who actively participated in a faith community and thereby responded to those prompts may have resulted in insufficient statistical power to detect a relationship between variables.

On an intrapersonal level, identifying as either bisexual or as a sexual minority but not as gay, lesbian, or bisexual contributed to increased identity uncertainty and reduced identity superiority, suggesting that attention should be paid to the variations in effects that the individuals' specific sexual minority identities may have on their sexual minority identity development. The finding that these individuals struggle more with understanding their sexual minority identities is not surprising, as within the current discourse around sexual minority identities, individuals who identity as bisexual or as other than gay or lesbian (i.e., queer, 
asexual, demisexual, etc.) are often neglected or systematically omitted, even if they remain a part of the LGB+ acronym (Greenesmith, 2010; Weiss, 2004). Similarly, other research has indicated that these individuals often feel less connected to the mainstream sexual minority community and identify less strongly with it, reducing their ability to receive those supports that are the most important for positive sexual minority identity development (Baldwin et al., 2015; Balsam \& Mohr, 2007; Callis, 2014; Herek, Norton, Allen, \& Sims, 2010). A similar phenomenon may be at play in terms of the differences between the groups on identity superiority, but the lack of significance on this aspect of sexual minority identity development between individuals who identify as an alternate sexual minority and those who identify as gay deserves further study as these individuals often experience distancing from the rest of the sexual minority community (Greenesmith, 2010), which might be expected to reduce feelings of identity superiority.

Overall, the results of this study are consistent with the noted importance of social engagement with other sexual minorities in traditional sexual minority identity formation models. The developmental models of Cass (1979), Troiden (1988), D'Augelli (1994), and Fassinger (1998) all highlight the interplay between intrapersonal and social factors during the sexual minority identity formation process; while the initial impetus toward the exploration of the possibility of a sexual minority identity comes from within individuals' psyches, the eventual development of a positive sexual minority identity depends on individuals not only recognizing and labeling their difference from the heterosexually identified majority, but also on developing a means to cope with that difference and to counteract the effects of a heterosexist and oftentimes openly homophobic social environment. This research has further demonstrated that supports from others are beneficial during this process, suggesting the importance of developing programming for young adults who identify as a sexual minority that can provide the necessary 
supports. While generalized support systems are beneficial for individuals' overall well-being, sexuality-related supports that take into account variations in individuals' unique sexual minority identities are critical for the advancement of young adults' sexual minority identity development.

\section{Limitations}

There are several limitations to this study. First, it was a cross-sectional inquiry, which does not allow causality to be established or for changes over time to be noted. Second, the sample only included individuals who identify as a sexual minority and attend postsecondary educational institutions in one state, limiting the generalizability of the findings. Third, the study design imposed a certain socially constructed view of sexuality by separating individuals who identify as a sexual minority into distinct categories, and, therefore, did not reflect more contemporary perspectives that advocate for a fluid conceptualization of sexual identity. Fourth, examining the differential experiences of individuals who identified within various racial and ethnic groups was not possible due to the lack of diversity in the study sample, preventing the exploration of differences based upon racial or ethnic identity. Fifth, it should be recognized that this study utilized one measure of perceived social supports and one measure of sexual minority identity formation. Finally, the two additional subscales added to the MSPSS that were created for this study were not evaluated for validity or reliability beyond face validity. Cronbach alphas on both scales were high, however, indicating a degree of reliability. In addition, it should be noted that each aspect of participants' lives encompasses a vast array of interconnected personal and social attributes and is subject to myriad competing influences. The instruments utilized in this study were designed to measure specific aspects of individuals' lives and may not reflect the entirety of any of the individuals' experiences. 


\section{Conclusion}

The results of this study contribute to the growing body of literature examining positive sexual minority identity formation at critical developmental junctures. Since the 1970s, there has been an increase in the focus on developmental frame-works among professionals and lay people (Bilodeau \& Renn, 2005), but little work has considered the effects of social supports on sexual minority identity development. By demonstrating the impact that different arenas of perceived social support have on various aspects of sexual minority identity development, this study has provided a base that researchers, professionals, universities, and community agencies can use to further tailor their interventions to address specific developmental needs. With more efficacious programming and services available, individuals who identify as a sexual minority will be better able to engage in the sexual minority identity developmental process within a context that supports a positive and coherent sense of self, thereby reducing mental health and interpersonal challenges. Further research is needed to better understand the intersection of individuals' multiple identities as well as how cultural perspectives related to sexual minorities impact sexual minority identity development, but this study has shown that certain types of support are beneficial for positive sexual minority identity development. 


\section{References}

Asakura, K. (2010). Queer youth space: A protective factor for sexual minority youth. Smith College Studies in Social Work, 80(4), 361-376.

Baldwin, A., Dodge, B., Schick, V., Hubach, R. D., Bowling, J., Malebranche, D., . . Fortenberry, J. D. (2015). Sexual self-identification among behaviorally bisexual men in the Midwestern United States. Archives of Sexual Behavior, 44(7), 2015-2026. doi:10.1007/s10508-014-0376-1

Balsam, K. F., \& Mohr, J. J. (2007). Adaptation to sexual orientation stigma: A comparison of bisexual and lesbian/gay adults. Journal of Counseling Psychology, 54(3), 306-319. doi:10.1037/0022-0167.54.3.306

Berg, R. C., Munthe-Kaas, H. M., \& Ross, M. W. (2016). Internalized homonegativity: A systematic mapping review of empirical research. Journal of Homosexuality, 63(4), 541558. doi:10.1080/00918369.2015.1083788

Bilodeau, B. L., \& Renn, K. A. (2005). Analysis of LGBT identity development models and implications for practice. New Directions for Student Services, 2005(111), 25-39. doi:10.1002/ss.171

Bregman, H. R., Malik, N. M., Page, M. J., Makynen, E., \& Lindahl, K. M. (2013). Identity profiles in lesbian, gay, and bisexual youth: The role of family influences. Journal of Youth \& Adolescence, 42(3), 417-430. doi:10.1007/s10964-012-9798-z

Brown, M., \& Colbourne, M. (2005). Bent but not broken: Exploring queer youth resilience. In M. Ungar (Ed.), Handbook for working with children and youth: Pathways to resilience across cultures and contexts (pp. 263-278). Thousand Oaks, CA: Sage.

Callis, A. S. (2014). Bisexual, pansexual, queer: Non-binary identities and the sexual borderlands. Sexualities, 17(1-2), 63-80. doi:10.1177/1363460713511094 
Calzo, J. P., Antonucci, T. C., Mays, V. M., \& D., C. S. (2011). Retrospective recall of sexual orientation identity development among gay, lesbian, and bisexual adults. Developmental Psychology, 47(6), 1658-1673. doi:10.1037/a0025508

Campos, D. (2005). Understanding gay and lesbian youth: Lessons for straight school teachers, counselors, and administrators. Lanham, MD: Rowman \& Littlefield Education.

Canty-Mitchell, J., \& Zimet, G. D. (2000). Psychometric properties of the Multidimensional Scale of Perceived Social Support in urban adolescents. American Journal of Community Psychology, 28(3), 391-400. doi:10.1023/A:1005109522457

Carrera, M. V., DePalma, R., \& Lameiras, M. (2012). Sex/gender identity: Moving beyond fixed and 'natural' categories. Sexualities, 15(8), 995-1016. doi:10.1177/1363460712459158

Cass, V. C. (1979). Homosexual identity formation: A theoretical model. Journal of Homosexuality, 4(3), 219-235. doi:10.1300/J082v04n03_01

Cass, V. C. (1984). Homosexual identity formation: Testing a theoretical model. Journal of Sex Research, 20, 143-167. doi:10.1080/00224498409551214

Craig, S. L., \& McInroy, L. (2014). You can form a part of yourself online: The influence of new media on identity development and coming out for LGBTQ youth. Journal of Gay \& Lesbian Mental Health, 18(1), 95-109. doi:10.1080/19359705.2013.777007

D'Augelli, A. R. (1994). Identity development and sexual orientation: Toward a model of lesbian, gay and bisexual identity development. In E. J. Trickett, R. J. Watts, \& D. Birman (Eds.), Human diversity: Perspectives on people in context (pp. 312-333). San Francisco, CA: Jossey-Bass.

D'Emilio, J., \& Freedman, E. B. (1998). Intimate matters: A history of sexuality in America (2nd ed.). Chicago, IL: University of Chicago Press. 
Diamond, L. M. (2008). Sexual fluidity: Understanding women's love and desire. Cambridge, MA: Harvard University Press.

DiFulvio, G. T. (2011). Sexual minority youth, social connection and resilience: From personal struggle to collective identity. Social Science \& Medicine, 72(10), 1611-1617. doi:10.1016/j.socscimed.2011.02.045

Doty, N. D., Willoughby, B. L. B., Lindahl, K. M., \& Malik, N. M. (2010). Sexuality related social support among lesbian, gay and bisexual youth. Journal of Youth and Adolescence, 39, 1134-1147. doi:10.1007/s10964-010-9566-x

Drescher, J. (2010). Queer diagnoses: Parallels and contrasts in the history of homosexuality, gender variance, and the Diagnostic and Statistical Manual. Archives of Sexual Behavior, 39, 427-460. doi:10.1007/s10508-009-9531-5

Dunn, M., Glassmann, D., Garrett, J. M., Badaszewski, P., Jones, G., Pierre, D., . . CorrellHughes, L. (2015). Faith and sexual orientation identity development in gay college men. Journal of Student Affairs Research \& Practice, 52(4), 374-386. doi:10.1080/19496591.2015.1050033

Eisenberg, M. E., \& Resnick, M. D. (2006). Suicidality among gay, lesbian and bisexual youth: The role of protective factors. Journal of Adolescent Health, 39(5), 662-668. doi:10.1016/j.jadohealth.2006.04.024

Eliason, M. J. (1996). An inclusive model of lesbian identity assumption. Journal of Gay Lesbian and Bisexual Identity, 1(1), 3-19.

Elizur, Y., \& Mintzer, A. (2001). A framework for the formation of gay male identity: Processes associated with adult attachment style and support from family and friends. Archives of Sexual Behavior, 30(2), 143-167. doi:10.1023/A:1002725217345 
Erikson, E. H. (1963). Childhood and society (2nd ed.). New York, NY: W. W. Norton \& Company, Inc.

Erikson, E. H. (1968). Identity: Youth and crisis. New York, NY: W. W. Norton \& Company.

Fassinger, R. E. (1998). Lesbian, gay, and bisexual identity and student development theory. In R. L. Sanlo (Ed.), Working with lesbian, gay, bisexual, and transgender college students: A handbook for faculty and administrators (pp. 13-22). Westport, CT: Greenwood Publishing Group.

Fetner, T., Elafros, A., Bortolin, S., \& Drechsler, C. (2012). Safe spaces: Gay-straight alliances in high schools. Canadian Review of Sociology, 49, 188-207. doi:10.1111/j.1755618X.2011.01290.x

Fine, L. E. (2016). “I can't do this right now”: Social integration, significant other support, and LGB educational trajectories. Sociological Focus, 49(3), 215-230. doi:10.1080/00380237.2016.1135608

Ford, V. E. (2003). Coming out as lesbian or gay: A potential precipitant of crisis in adolescence. Journal of Human Behavior in the Social Environment, 8(2/3), 93-110.

Fox, R. C. (1995). Bisexual identities. In A. R. D'Augelli \& C. J. Patterson (Eds.), Lesbian, gay, and bisexual identities over the lifespan: Psychological perspectives (pp. 48-86). New York, NY: Oxford University Press.

Gottlieb, A. R. (Ed.) (2005). Side by side: On having a gay or lesbian sibling. Philadelphia, PA: Haworth Press, Inc.

Greenesmith, H. (2010). Drawing bisexuality back into the picture: How bisexuality fits into LGBT legal strategy ten years after bisexual erasure. Cardozo Journal of Law and Gender, 17, 65-80. 
Grierson, J., \& Smith, A. M. (2005). In from the outer: Generational differences in coming out and gay identity formation. Journal of Homosexuality, 50(1), 53-70. doi:10.1300/J082v50n01_03

Groh, D. R., Jason, L. A., \& Keys, C. B. (2008). Social network variables in Alcoholics Anonymous: A literature review. Clinical Psychology Review, 28(3), 430-450. doi:10.1016/j.cpr.2007.07.014

Halpin, S. A., \& Allen, M. W. (2004). Changes in psychosocial well-being during stages of gay identity development. Journal of Homosexuality, 47(2), 109-126. doi:10.1300/J082v47n02_07

Herek, G. M., Norton, A. T., Allen, T. J., \& Sims, C. L. (2010). Demographic, psychological, and social characteristics of self-identified lesbian, gay, and bisexual adults in a US probability sample. Sexuality Research and Social Policy, 7(3), 176-200. doi:10.1007/s13178-010-0017-y

Hombrados-Mendieta, M. I., Gomez-Jacinto, L., Dominguez-Fuentes, J. M., Garcia-Levia, P., \& Castro-Travé. (2011). Types of support provided by parents, teachers, and classmates during adolescence. Journal of Community Psychology, 40(6), 645-664. doi:10.1002/jcop.20523

Hunter, M. A. (2010). All the gays are white and all the blacks are straight: Black gay men, identity, and community. Sexuality Research and Social Policy, 7(2), 81-92. doi:10.1007/s13178-010-0011-4

Johnson, M. J., \& Amella, E. J. (2014). Isolation of lesbian, gay, bisexual and transgender youth: A dimensional concept analysis. Journal of Advanced Nursing, 70(3), 523-532. doi:10.1111/jan.12212 
King, M., Semlyen, J., Tai, S. S., Killaspy, H., Osborn, D., Popelyuk, D., \& Nazareth, I. (2008). A systematic review of mental disorder, suicide, and deliberate self harm in lesbian, gay and bisexual people. BMC Psychiatry, 80(70). doi:10.1186/1471-244X-8-70

Konishi, C., \& Hymel, S. (2009). Bullying and stress in early adolescence: The role of coping and social support. The Journal of Early Adolescence, 29(3), 333-356. doi:10.1177/0272431608320126

Kosciw, J. G., Greytak, E. A., Bartkiewicz, M. J., Boesen, M. J., \& Palmer, N. A. (2011). The 2011 national school climate survey: The experiences of lesbian, gay, bisexual and transgender youth in our nation's schools. Retrieved from New York:

Kubicek, K., McDavitt, B., Carpineto, J., Weiss, G., Iverson, E. F., \& Kipke, M. D. (2009). "God made me gay for a reason": Young men who have sex with men's resiliency in resolving internalized homophobia from religious sources. Journal of Adolescent Research, 24, 601-633. doi:10.1177/0743558409341078

LaSala, M. C. (2012). Coming out, coming home: Helping families to adjust to a gay or lesbian child. New York, NY: Columbia University Press.

Mallon, G. P. (2010). LGBTQ youth issues: Practical guide for youth workers serving lesbian, gay, bisexual, transgender and questioning youth. New York, NY: Child Welfare League of America.

Marine, S. (2011). Special issue: Stonewall's legacy - bisexual, gay, lesbian, and transgender students in higher education. ASHE Higher Education Report, 37(4), 1-145. doi:10.1002/aehe.3704

McCormick, A., Schmidt, K., \& Clifton, E. (2014). Gay-straight alliances: Understanding their impact on the academic and social experiences of lesbian, gay, bisexual, transgender, and 
questioning high school students. Children \& Schools, 37(2), 71-77.

doi:10.1093/cs/cdu028

Meanley, S., Pingel, E. S., \& Bauermeister, J. A. (2015). Psychological well-being among religious and spiritual-identified young gay and bisexual men. Sexuality Research and Social Policy, 13(1), 35-45. doi:10.1007/s13178-015-0199-4

Meyer, I. H. (2013). Prejudice, social stress, and mental health in lesbian, gay, and bisexual populations: Conceptual issues and research evidence. Psychology of Sexual Orientation and Gender Diversity, 1(S), 3-26. doi:10.1037/2329-0382.1.S.3

Mishna, F., Newman, P. A., Daley, A., \& Solomon, S. (2009). Bullying of lesbian and gay youth: A qualitative investigation. British Journal of Social Work, 39, 1598-1614. doi:10.1093/bjsw/bcm148

Mohr, J. J., \& Fassinger, R. E. (2000). Measuring dimensions of lesbian and gay male experience. Measurement and Evaluation in Counseling and Development, 33, 66-90.

Mohr, J. J., \& Kendra, M. S. (2011). Revision and extension of a multidimensional measure of sexual minority identity: The lesbian, gay and bisexual identity scale. Journal of Counseling Psychology, 58(2), 234-245.

Morgan, E. M. (2011). Not always a straight path: College students' narratives of heterosexual identity development. Sex Roles, 66(1-2), 79-93. doi:10.1007/s11199-011-0068-4

Palmer, N. A., Kosciw, J. G., \& Bartkiewicz, M. J. (2012). Strengths and silences: The experiences of lesbian, gay, bisexual and transgender students in rural and small town schools. Retrieved from New York:

Roe, S. L. (2015). Examining the role of peer relationships in the lives of gay and bisexual adolescents. Children \& Schools, 37(2), 117-124. doi:10.1093/cs/cdv001 
Rosario, M., Schrimshaw, E. W., \& Hunter, J. (2004). Ethnic/racial differences in the comingout process of lesbian, gay, and bisexual youths: A comparison of sexual identity development over time. Cultural Diversity \& Ethnic Minority Psychology, 10(3), 215228. doi:10.1037/1099-9809.10.3.215

Rosario, M., Schrimshaw, E. W., \& Hunter, J. (2008). Predicting different patterns of sexual identity development over time among lesbian, gay and bisexual youths: A cluster analytic approach. American Journal of Community Psychology, 42(3-4), 266-282. doi:10.1007/s 10464-008-9207-7

Rosario, M., Schrimshaw, E. W., \& Hunter, J. (2011). Different patterns of sexual identity development over time: Implications for the psychological adjustment of lesbian, gay, and bisexual youth. Journal of Sex Research, 48(1), 3-15. doi:10.1080/00224490903331067

Rosario, M., Schrimshaw, E. W., Hunter, J., \& Braun, L. (2006). Sexual identity development among lesbian, gay, and bisexual youths: Consistency and change over time. Journal of Sex Research, 43(1), 46-58. doi:10.1080/00224490609552298

Savin-Williams, R. C. (2001). A critique of the research on sexual-minority youths. Journal of Adolescence, 24, 5-13. doi:10.1006/jado.2000.0369

Savin-Williams, R. C. (2005). The new gay teenager. Cambridge, MA: Harvard University Press.

Savin-Williams, R. C., \& Ream, G. L. (2007). Prevalence and stability of sexual orientation components during adolescence and young adulthood. Archives of Sexual Behavior, 36(3), 385-394. doi:10.1007/s10508-006-9088-5 
Schmidt, C. K., Miles, J. R., \& Welsh, A. C. (2011). Perceived discrimination and social support: The influences on career development and college adjustment of LGBT college students. Journal of Career Development, 38(4), 293-309. doi:10.1177/0894845310372615

Sheets, R. L., \& Mohr, J. J. (2009). Perceived social support from friends and family and psychosocial functioning in bisexual young adult college students. Journal of Counseling Psychology, 56(1), 152-163. doi:10.1037/0022-0167.56.1.152

Shidlo, A. (1994). Internalized homophobia: Conceptual and empirical issues in measurement. In B. Greene \& G. M. Herek (Eds.), Lesbian and gay psychology: Theory, research and clinical application (pp. 176-205). Thousand Oaks, CA: Sage.

Tate, Y. B. (2007). Using Erikson's developmental theory to understand and nurture spiritual development in Christians. Journal of Psychology and Christianity, 26(3), 218-226.

Tharinger, D., \& Wells, G. (2000). An attachment perspective on the developmental challenges of gay and lesbian adolescents: The need for continuity of caregiving from family and schools. School Psychology Review, 29(2), 158-172.

Theodore, J. L., Shidlo, A., Zemon, V., Foley, F. W., Dorfman, D., Dalhman, K. L., \& Hamid, S. (2013). Psychometrics of an internalized homophobia instrument for men. Journal of Homosexuality, 60(4), 558-574. doi:10.1080/00918369.2013.760304

Troiden, R. R. (1988). Gay and lesbian identity: A sociological analysis. Dix Hills: General Hall. Umaña-Taylor, A. J., Yazedjian, A., \& Bámaca-Gómez, M. (2004). Developing the ethnic identity scale using Eriksonian and social identity perspectives. Identity: An International Journal of Theory and Research, 4(1), 9-38. doi:10.1207/S1532706XID0401_2

Walls, N. E., Wisneski, H., \& Kane, S. B. (2013). School climate, individual support or both? Gay-straight alliances and the mental health of sexual minority youth. School Social Work Journal, 37(2), 88-111. doi:10.1177/0044118X09334957 
Weiss, J. T. (2004). GL vs. BT: The archaeology of biphobia and transphobia within the US gay and lesbian community. Journal of Bisexuality, 3(3-4), 25-55.

doi:10.1300/J159v03n03_02

Winbush, R. A. (1977). A quantitative exploration into the theoretical formulations of Erik H. Erikson concerning Black identity. Dissertation Abstracts International, 37(9-B), 47154716.

Wright, E. R., \& Perry, B. L. (2006). Sexual identity distress, social support, and the health of gay, lesbian, and bisexual youth. Journal of Homosexuality, 51(1), 81-110. doi:10.1300/J082v51n01_05

Yarhouse, M. A., Stratton, S. P., Dean, J. B., \& Brooke, H. L. (2009). Listening to sexual minorities on Christian college campuses. Journal of Psychology and Theology, 37(2), 96-113.

Zimet, G. D., Dahlem, N. W., Zimet, S. G., \& Farley, G. K. (1988). The Multidimensional Scale of Perceived Support. Journal of Personality Assessment, 52, 30-41. doi:10.1207/s15327752jpa5201_2 


\section{Tables}

Table 1: MSPS and LGBIS Subscales Correlations

\begin{tabular}{|c|c|c|c|c|c|c|c|c|c|c|c|c|}
\hline & $\begin{array}{l}\text { MSPSS } \\
\text { Sig Other }\end{array}$ & $\begin{array}{c}\text { MSPSS } \\
\text { Campus } \\
\text { Grp }\end{array}$ & $\begin{array}{l}\text { MSPSS } \\
\text { Friends }\end{array}$ & $\begin{array}{l}\text { MSPSS } \\
\text { Family }\end{array}$ & $\begin{array}{l}\text { MSPSS } \\
\text { Faith }\end{array}$ & $\begin{array}{c}\text { LGBIS } \\
\text { Con } \\
\text { Motiv }\end{array}$ & $\begin{array}{c}\text { LGBIS } \\
\text { Dif } \\
\text { Process }\end{array}$ & $\begin{array}{c}\text { LGBIS } \\
\text { Ident } \\
\text { Super }\end{array}$ & $\begin{array}{c}\text { LGBIS } \\
\text { Ident } \\
\text { Cent }\end{array}$ & $\begin{array}{c}\text { LGBIS } \\
\text { Ident } \\
\text { Uncert }\end{array}$ & $\begin{array}{c}\text { LGBIS } \\
\text { Int } \\
\text { Homoneg } \\
\end{array}$ & $\begin{array}{c}\text { LGBIS } \\
\text { Ident } \\
\text { Affirm }\end{array}$ \\
\hline MSPSS Campus Grp & $.508 * * *$ & - & & & & & & & & & & \\
\hline MSPSS Friends & $.507 * * *$ & .160 & - & & & & & & & & & \\
\hline MSPSS Family & .006 & -.088 & $.245 *$ & - & & & & & & & & \\
\hline MSPSS Faith & $.291 *$ & $.407 * *$ & $.284 *$ & $.407 * *$ & - & & & & & & & \\
\hline LGBIS Con Motivation & -.103 & .140 & $-.205 *$ & $-.287 * *$ & .035 & - & & & & & & \\
\hline LGBIS Dif Process & $-.241 *$ & -.049 & $-.159 \dagger$ & $-.278 * *$ & -.149 & $.360 * * *$ & - & & & & & \\
\hline LGBIS Ident Superiority & .086 & .092 & .073 & .079 & .181 & -.115 & -.137 & - & & & & \\
\hline LGBIS Ident Centrality & .037 & $.349 * *$ & -.021 & -.055 & .114 & -.071 & .069 & $.337 * * *$ & - & & & \\
\hline LGBIS Ident Uncertainty & -.147 & -.016 & $-.339 * * *$ & -.116 & -.105 & $.227 * *$ & $.319 * * *$ & -.103 & -.112 & - & & \\
\hline $\begin{array}{l}\text { LGBIS Internal } \\
\text { Homoneg }\end{array}$ & $-.304 * *$ & $-.259 *$ & $-.188 *$ & -.122 & .002 & $.257 * *$ & $.355 * * *$ & -.086 & $-.263 * *$ & $.160 t$ & - & \\
\hline LGBIS Ident Affirm & $.334 * * *$ & $.474 * * *$ & $.243 * *$ & .034 & .132 & $-.246 * *$ & $-.238 * *$ & $.177 *$ & $.635 * * *$ & $-.189 *$ & $-.521 * * *$ & - \\
\hline LGBIS Accept Con & $-.245 *$ & -.131 & $-.269 * *$ & $-.280 * *$ & -.132 & $.433 * * *$ & $.424 * * *$ & .008 & $.210 *$ & $.197 *$ & $.397 * * *$ & -.111 \\
\hline
\end{tabular}

$+p<.10 ; \quad * p<.05 ; \quad * * p<.01 ; \quad * * * p<.001$ 
Table 2: Demographics of Study Participants ${ }^{\text {a }}$

\begin{tabular}{|c|c|c|}
\hline & $n$ & $\%$ \\
\hline \multicolumn{3}{|l|}{ Gender } \\
\hline Male & 37 & 28.7 \\
\hline Female & 82 & 63.6 \\
\hline Prefer Not to Say / Other & 10 & 7.8 \\
\hline \multicolumn{3}{|l|}{ Sexual Minority Identity } \\
\hline Lesbian (Female) & 34 & 26.4 \\
\hline Gay (Male) & 32 & 24.8 \\
\hline Bisexual & 41 & 31.8 \\
\hline Other Sexual Minority & 22 & 17.1 \\
\hline \multicolumn{3}{|l|}{ Race } \\
\hline Black or African-American & 5 & 3.9 \\
\hline Asian & 2 & 1.6 \\
\hline White & 112 & 87.5 \\
\hline Native American or Other Pacific Islander & 2 & 1.6 \\
\hline Other (Please Specify) & 7 & 5.4 \\
\hline \multicolumn{3}{|l|}{ Ethnicity } \\
\hline Not Hispanic / Latino & 119 & 92.2 \\
\hline Hispanic / Latino & 10 & 7.8 \\
\hline \multicolumn{3}{|l|}{ Participation in a Faith Community } \\
\hline Does Not Participate & 87 & 67.4 \\
\hline Participates & 42 & 32.6 \\
\hline \multicolumn{3}{|l|}{ Participation in a Campus Group for Sexual Minorities } \\
\hline Does Not Participate & 55 & 42.6 \\
\hline Participates & 74 & 57.4 \\
\hline
\end{tabular}


Table 3a: Results of Hierarchical Multiple Regression for LGBIS Subscales

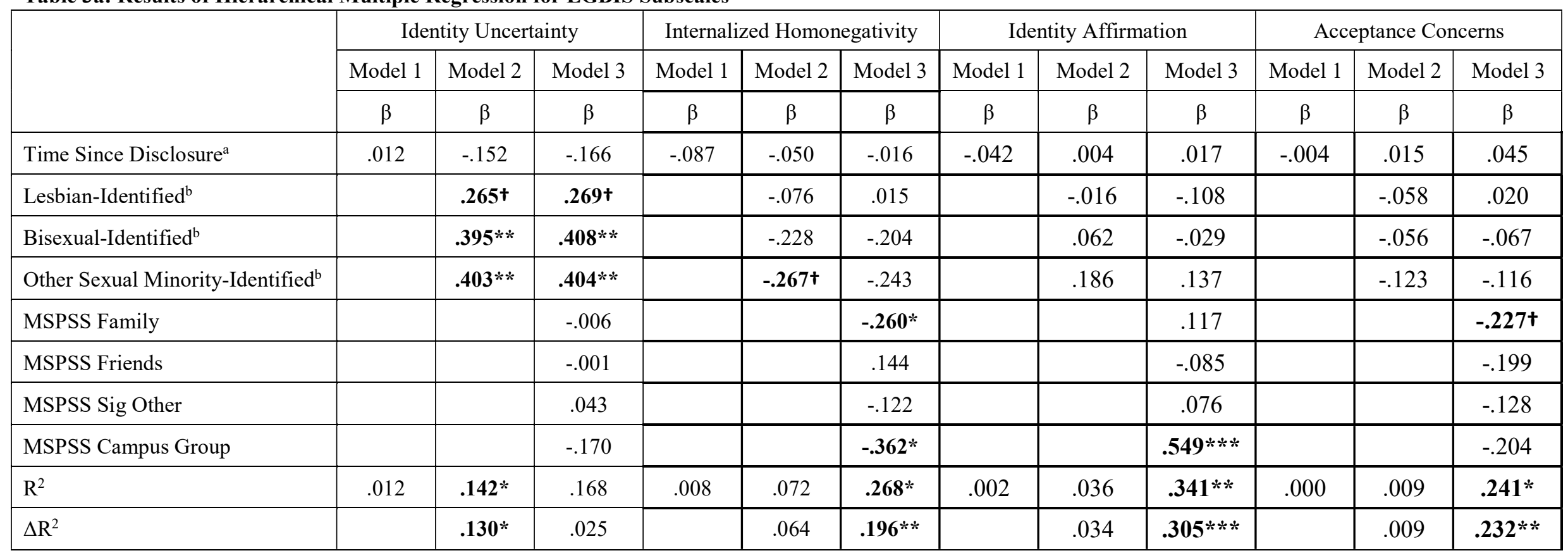

Notes: All $n=70$

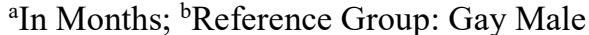

${ }^{\dagger} p<.10 ; * p<.05 ; * * p<.01 ; * * * p<.001$ 


\begin{tabular}{|c|c|c|c|c|c|c|c|c|c|c|c|c|}
\hline & \multicolumn{3}{|c|}{ Identity Superiority } & \multicolumn{3}{|c|}{ Concealment Motivation } & \multicolumn{3}{|c|}{ Identity Centrality } & \multicolumn{3}{|c|}{ Difficult Process } \\
\hline & Model 1 & Model 2 & Model 3 & Model 1 & Model 2 & Model 3 & Model 1 & Model 2 & Model 3 & Model 1 & Model 2 & Model 3 \\
\hline & $\beta$ & $\beta$ & $\beta$ & $\beta$ & $\beta$ & $\beta$ & $\beta$ & $\beta$ & $\beta$ & $\beta$ & $\beta$ & $\beta$ \\
\hline Time Since Disclosure $^{\mathrm{a}}$ & .159 & .139 & .152 & .021 & .061 & .089 & .016 & -.019 & -.002 & -.122 & -.125 & -.099 \\
\hline Lesbian-Identified $^{b}$ & & $-.429 * *$ & $-.462 * *$ & & -.145 & -.114 & & -.101 & -.142 & & -.066 & .013 \\
\hline Bisexual-Identified $^{b}$ & & $-.513 * *$ & $-.580 * * *$ & & .229 & .218 & & -.128 & -.200 & & -.051 & -.030 \\
\hline Other Sexual Minority-Identified ${ }^{b}$ & & -.211 & -.247 & & -.136 & -.132 & & .082 & .047 & & -.021 & .002 \\
\hline MSPSS Family & & & -.021 & & & -.098 & & & .020 & & & -.187 \\
\hline MSPSS Friends & & & -.158 & & & -.018 & & & -.195 & & & -.011 \\
\hline MSPSS Sig Other & & & .036 & & & -.090 & & & .010 & & & -.129 \\
\hline MSPSS Campus Group & & & .205 & & & .039 & & & $.348^{*}$ & & & $-.237 \dagger$ \\
\hline $\mathrm{R}^{2}$ & .025 & $.208 * *$ & $.253^{*}$ & .000 & $.119 \dagger$ & .137 & .000 & .034 & .140 & .015 & .018 & .148 \\
\hline$\Delta \mathrm{R}^{2}$ & & $.183 * *$ & .045 & & $.118^{*}$ & .018 & & .034 & .106 & & .003 & $.130+$ \\
\hline \multicolumn{13}{|l|}{$\begin{array}{l}\text { Notes: All } n=70 \\
{ }^{\mathrm{a} I n} \text { Months; }{ }^{\mathrm{b}} \text { Refe } \\
{ }^{\dagger} p<.10 ; * p<.05\end{array}$} \\
\hline
\end{tabular}




\section{Appendix A}

\section{Modified Multidimensional Scale of Perceived Social Supports}

We are interested in how you feel about the following statements. Read each statement carefully. Indicate how you feel about each statement as it relates to your sexual minority identity.

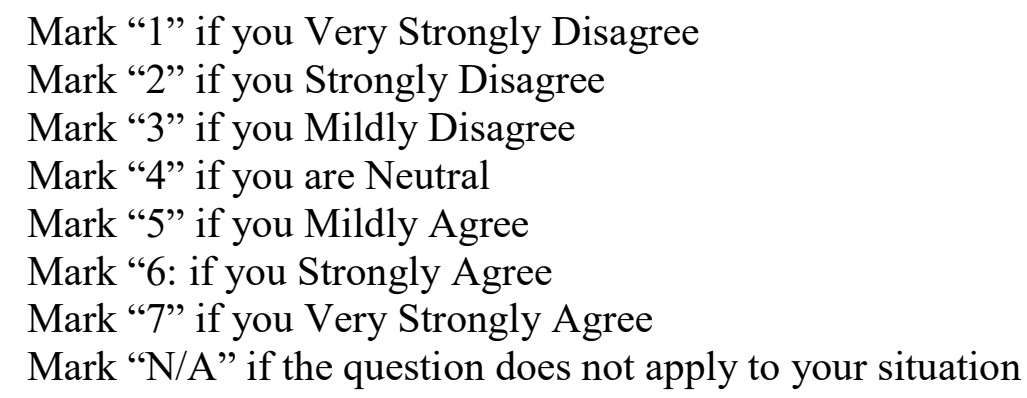

There is a special person who is around when I am in need.

There is a special person with whom I can share joys and sorrows.

My family really tries to help me.

I get the emotional help and support I need from my family.

I have a special person who is a real source of comfort to me.

My friends really try to help me.

I can count on my friends when things go wrong.

I can talk about my problems with my family.

I have friends with whom I can share my joys and sorrows.

There is a special person in my life who cares about my feelings.

My family is willing to help me make decisions.

I can talk about my problems with my friends.

My faith community is a source of comfort to me.*

I have a faith community that accepts me.*

I can count on my faith community when I have personal needs.*

My faith community provides a place where I can be with people that care about me.*

My LGB campus group is a place where I can meet other LGB people.*

My LGB campus group provides a group of people with whom I can be myself.*

I feel supported when I am with the members of my LGB campus group.*

My LGB campus group provides a place where I can openly express my feelings.*

*indicates a prompt developed for this study 